\title{
Intracerebral hemorrhage in the oldest old: a population-based study (Vantaa 85+)
}

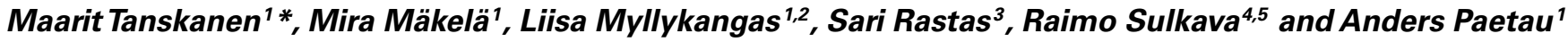 \\ ${ }^{1}$ Department of Pathology, Haartman Institute, University of Helsinki and HUSLAB, Helsinki, Finland \\ ${ }^{2}$ Folkhälsan Institute of Genetics, Biomedicum Helsinki, Helsinki, Finland \\ ${ }^{3}$ Lohja Hospital, Lohja, Finland \\ ${ }^{4}$ Institute of Public Health and Clinical Nutrition, University of Eastern Finland, Kuopio, Finland \\ ${ }^{5}$ Department of Neurology, Kuopio University Hospital, Kuopio, Finland
}

\section{Edited by:}

Steven M. Greenberg, Harvard, USA

Reviewed by:

Carlos Kase, Boston University, USA

Stefano Ricci, Università degli Studi di

Perugia, Italy

Eitan Auriel, Partners Healthcare, USA

*Correspondence:

Maarit Tanskanen, Department of

Pathology, Haartman Institute,

University of Helsinki,

Haartmaninkatu 3, PO Box 21,

Helsinki 00140, Finland.

e-mail: maarit.tanskanen@helsinki.fi
Aims: Very elderly subjects represent the fastest growing population in the world. Most of the recent studies on intracerebral hemorrhage $(\mathrm{ICH})$ have been carried out on younger patients and/or preferably using novel radiological techniques. We investigated the prevalence, risk factors, and histopathological characteristics of the $\mathrm{ICH}$ in the oldest old. Materials and methods: The brains of 300 autopsied individuals (248 females, 52 males, mean age at death $92.4 \pm 3.7$ years) were investigated as part of the prospective population-based Vantaa $85+$ study. After macroscopic investigation, the presence and extent of microscopic brain hemorrhages $(\mathrm{MH})$ were analyzed by counting the number of iron containing macrophages (siderophages) by Prussian blue staining. Deposits with $>5$ siderophages were defined as $\mathrm{MH}+$, forming a subgroup of $\mathrm{MH}$. Genotyping of apolipoprotein $E$ (APOE) and the analysis of microscopic (MI) or larger infarctions and cerebral amyloid angiopathy (CAA) were performed using standardized methods. Regression analysis was used to predict the presence of $\mathrm{ICH}$, with and without co-localized CAA, and was adjusted for age at death and gender. Results: The prevalence of macroscopic $\mathrm{ICH}$ was $2.3 \%$ in total; consisting of $1 \%$ large lobar hemorrhage (LH), $1 \%$ deep hemorrhage $(\mathrm{DH})$, and $0.3 \%$ of subarachnoid hemorrhage (SAH). $62 \%$ had $\mathrm{MH}$ and $15.3 \% \mathrm{MH}+$. All $\mathrm{MH}+$ lesions were found to be $>2 \mathrm{~mm}$ wide. $55.9 \%$ of subjects with $\mathrm{MH}$ and $81.2 \%$ of those with $\mathrm{MH}+$ showed $\mathrm{MH} / \mathrm{MH}+$ and $\mathrm{CAA}$ in the same brain region (MHCAA and $\mathrm{MH}+\mathrm{CAA}$, respectively). $\mathrm{MH}$ was associated with none of the neuropathological or clinical conditions, nor with the $A P O E$ carrier status. The subjects with $\mathrm{MH}+, \mathrm{MHCAA}$ or $\mathrm{MH}+\mathrm{CAA}$ carried the APOE \&4 allele more frequently than controls (OR 3.681, 3.291, 7.522, respectively). Siderophages in $\mathrm{MH}+\mathrm{CAA}$ co-localized with $\mathrm{CAA}$ and with two-thirds of the $\mathrm{Ml}$ in the tissue sections. Conclusion: Macroscopic ICH was rare in the very elderly. $\mathrm{MH}$ was frequent and clinically insignificant. $\mathrm{MH}+$ was rare but closely related with the APOE $\varepsilon 4$ genotype and the presence of severe CAA and infarction.

Keywords: intracerebral hemorrhage, cerebral amyloid angiopathy, microinfarction, apolipoprotein $E \varepsilon 4$ allele

\section{INTRODUCTION}

Lobar hemorrhage (LH) and deep hemorrhage in the basal ganglia-thalamus region (DH) are life-threatening end stage complications of cerebral amyloid angiopathy (CAA) and hypertension, respectively. These lesions are mostly diagnosed in subjects aged 60-70 years. Cerebral microhemorrhages, "focal deposits of red blood cells and hemosiderin" (Fazekas et al., 1999), can be detected using the gradient echo T2*-weighted MRI scan. The microscopic hemorrhagic lesions detected in MRI (microbleeds) are suggested to be related to CAA (Vernooij et al., 2008; Dierksen et al., 2010). This is supported by (1) the increasing prevalence of microbleeds and CAA with age (Vinters and Gilbert, 1983; Vernooij et al., 2008; Poels et al., 2010), and (2) lobar microbleeds being strictly associated with the possession of the apolipoprotein $E(A P O E) \varepsilon 4$ allele (Vernooij et al., 2008) or APOE $\varepsilon 4 / 4$ genotype (Sveinbjornsdottir et al., 2008), similar to CAA (Yamada, 2002).
The histopathological characteristics of intracerebral hemorrhage $(\mathrm{ICH})$ include tissue edema, neuronal changes, activation of the microglia, infiltration of the hematogenous macrophages, and phagocytosis of the erythrocytes by phagocytic cells (Koeppen et al., 1995; Qureshi et al., 2001; Zhao et al., 2009). Spontaneous bleeding in the brain can also result from hemorrhagic transformation of an ischemic brain lesion (Balami et al., 2011). Histopathological studies of microscopic hemorrhagic lesions in the cerebral cortex and/or subcortical regions are scarce. In a subset ( $\geq 95$ years) of the Vantaa population they were more frequent in the subjects with CAA than in those without (Tanskanen et al., 2005). A recent histopathological study reported a microbleed in the subcortical white matter of occipital lobe in 1 in 12 elderly subjects (Fisher et al., 2010).

The very elderly ( $\geq 85$ years) is the fastest growing age group in the world. Most studies of ICH have been carried out on younger 
subjects, and the recent use of novel radiological techniques have provided extensive information of the condition. We aimed to (1) investigate the prevalence and risk factors of $\mathrm{ICH}$ in the oldest old in a population-based material, and (2) compare the severity and topography of microscopic hemorrhagic lesions with other neuropathologies at the tissue level.

\section{MATERIALS AND METHODS}

\section{VANTAA 85+ STUDY PROTOCOL AND PARTICIPANTS}

The prospective and population-based Vantaa $85+$ Study began in 1991 and included all individuals aged $\geq 85$ years living in the city of Vantaa in Southern Finland on April 1, 1991. The clinical follow-up studies were carried out in 1994, 1996, 1999, and 2001. Of all the 601 eligible subjects 553 participated in the clinical study. Post-mortem examinations were performed on 306/553 $(55.3 \%)$. Of these, two had denied to participate in the clinical study and four were excluded because of insufficient clinical data. The present study is based on these 300 subjects $(52,17.3 \%)$ males, with mean age at death $92.4 \pm 3.7$ years (males $92.1 \pm 3.6$ years). Table 1 shows the characteristics of the autopsied and clinically investigated populations.

\section{CLINICAL EXAMINATION}

The participants were interviewed by a trained nurse, conducted using a structured questionnaire consisting of questions concerning health, health-related behavior, and medication. Clinical examination included general physical examination and neurological examination by a neurologist. The diagnosis of dementia was based on the criteria provided by the Diagnostic and Statistical Manual of Mental Disorders, 3rd edition, revised (DSM III-R; American Psychiatric Association, 1987), and was based on a consensus diagnosis of two neurologists. Subjects were classified as hypertensive if they used any blood pressure lowering medication.

Table 1 | Demographic features of the autopsied subpopulation compared with the whole Vantaa $85+$ study population.

\begin{tabular}{|c|c|c|}
\hline & Autopsied, N (\%) & $\begin{array}{l}\text { Clinically } \\
\text { examined, } N(\%)\end{array}$ \\
\hline & $300(54.2)$ & $553(100)$ \\
\hline \multirow[t]{2}{*}{ Age at death (year $\pm S D$; range) } & $92.4 \pm 3.7$ & $92.3 \pm 3.8$ \\
\hline & $(85.1-105.6)$ & (85.1-105.7) \\
\hline Male gender & $52(17.3)$ & $113(18.8)$ \\
\hline Dementia & $195(65.0)$ & $314(52.2)$ \\
\hline Hypertension ${ }^{a}$ & $74(24.7)$ & $142(25.8)$ \\
\hline Antith/antico ${ }^{b}$ & $37(12.3)$ & $97(16.1)$ \\
\hline$A P O E$ \&2-allele carrier & $32^{c}(11.5)$ & $79^{d}(13.1)$ \\
\hline APOE \&3-allele carrier & $269^{c}(89.7)$ & $508^{d}(84.5)$ \\
\hline APOE $\varepsilon 4$-allele carrier & $88^{c}(31.7)$ & $155^{d}(25.8)$ \\
\hline
\end{tabular}

$S D$, standard deviation; Antith/antico, antithrombotic/anticoagulation medication; APOE, apolipoprotein E.

${ }^{a}$ Diagnosis based on the use of blood pressure lowering medication.

${ }^{\circ} A S A$, warfarin, or dipyramidole.

${ }^{c} A P O E$ genotyping performed on 278.

${ }^{d}$ APOE genotyping performed on 532 .
Antithrombotic/anticoagulation medication consisted of acetyl salicylic acid (ASA), warfarin, or dipyramidole.

\section{AUTOPSY WITH NEUROPATHOLOGICAL EXAMINATION}

After the autopsy the brains were fixed in $4 \%$ phosphate-buffered formaldehyde for at least 2 weeks. The presence and extent of arteriosclerosis of the cerebral blood vessels was analyzed macroscopically. The cerebrum was cut in $1 \mathrm{~cm}$ thick coronal slices and the brain stem and cerebellum in approximately $5 \mathrm{~mm}$ thick sagittal slices. The presence and location of macroscopic intracerebral (deep, DH and lobar, LH) or superficial (subarachnoid, SH) hemorrhagic lesions was recorded.

\section{MICROSCOPIC ANALYSES}

The diagnosis of the microscopic variables was based on the consensus of at least two experienced neuropathologists/pathologists.

\section{Microscopic hemorrhages}

We defined the presence of old microscopic brain hemorrhages $(\mathrm{MH})$ as areas with iron containing macrophages (siderophages) in the brain tissue. $\mathrm{MH}$ was assessed in six brain regions (frontal, parietal, temporal and occipital lobes, hippocampus and cerebellum). Approximately $25 \times 20 \mathrm{~mm}$ wide and 5-6 $\mu \mathrm{m}$ thick tissue slides, containing both cortex and subcortical white matter, were stained with the histological Prussian blue stain. We counted the number of cortical and subcortical siderophages and defined deposits with $>5$ siderophages in the tissue section as $\mathrm{MH}+$, as a subgroup of $\mathrm{MH}$. $\mathrm{MH}$ and $\mathrm{MH}+$ were used as bivariate variables and the number of brain regions (0-6) with $\mathrm{MH}$ as an ordinal variable in the statistical analyses. We did not record (1) vascular iron positivity associated with calcium deposition, observed as dark blue staining in the H\&E stained sections (ferrocalcinosis), which was frequently encountered in the cerebellar dentate nucleus and/or choroid plexus region (Vernooij et al., 2008) or (2) subcortical purely perivascular iron deposits.

\section{Ischemic lesions}

Cortical microinfarctions (MI) were analyzed in the H\&E stained tissue sections in the six brain regions described above. The MI was defined as a focal lesion $\leq 1 \mathrm{~mm}^{2}$ with neuronal loss, glia cell and macrophage reaction and/or cystic tissue necrosis, and being invisible to the naked eye.

\section{Cerebral amyloid angiopathy}

The presence of CAA was analyzed in six brain regions (see above) as previously described (Tanskanen et al., 2012). The diagnosis of CAA was based on Congo red staining and confirmed using immunohistochemistry (IHC) against amyloid beta $(\mathrm{A} \beta)$ peptide (clone $4 \mathrm{G} 8$, detecting amino acids $17 \rightarrow 24$ ). The severity of CAA was assessed in two ways. First, the percentage of blood vessels with CAA was analyzed separately for parenchymal and leptomeningeal blood vessels in each tissue section of the six brain regions investigated. The parenchymal and leptomeningeal scores were combined and the total score for each subject was counted by adding up the combined scores of the six brain regions and dividing the result by six. Severe CAA was defined as the percentage of blood vessels with CAA $>5.3 \%$ (the upper quartile (UQ) value for 
CAA severity in all six brain regions). Cases with the severity value for CAA $\leq 5.3 \%$ blood vessels with CAA were defined as mild/no CAA. Secondly, the number of brain regions with CAA (0-6) was counted.

\section{Microscopic hemorrhage with cerebral amyloid angiopathy}

The presence and number of tissue sections showing both $\mathrm{MH}$ or $\mathrm{MH}+$ and CAA was counted. The sections with $\mathrm{MH}$ and CAA were designated as MHCAA and the sections with $\mathrm{MH}+$ and CAA as $\mathrm{MH}+\mathrm{CAA}$. Next, the Prussian blue, Congo red, $\mathrm{H} \& \mathrm{E}$, and $\mathrm{A} \beta$ IHC stained tissue sections from samples with $\mathrm{MH}+/ \mathrm{MH}+\mathrm{CAA}$ were analyzed in parallel to investigate the possible co-localization of siderophages with CAA/MI or larger ischemic lesions. Other samples, i.e., those with $\leq 5$ sideropahges in the tissue could not be systematically analyzed this way for two reasons: (1) The Prussian blue and Congo red stained sections were not always consecutive, thus the siderophages in Prussian blue stained sections only seldom could be visible in the Congo red stained sections, and (2) although the siderophages stain brown in Congo red, the pigment cannot be reliably differentiated from other pigments with Congo red only.

\section{Alzheimer's disease-related pathologies}

The CERAD scores and Braak stages to investigate the AD-related neuropathologies were defined as originally described (Braak and Braak, 1991; Mirra et al., 1991).

\section{GENETIC ANALYSES}

APOE genotyping was carried out as previously described (Myllykangas et al., 2002).

\section{STATISTICAL ANALYSES}

Statistical analyses were performed using the SPSS (PASW) for Windows version 20 software. Bivariate logistic regression analysis was used to predict the presence of ICH, MHCAA, and MH+CAA (univariate analysis, adjusted for age at death and gender). Correlation between the number of brain regions with $\mathrm{MH}, \mathrm{MH}+$, and CAA was performed using Spearman correlation analysis.

\section{APPROVAL FOR THE STUDY}

The Vantaa $85+$ study was approved by the Ethics Committee of the Health Center of the City of Vantaa. The Finnish Health and Social Ministry approved the use of the health and social work records and death certificates. The National Authority for Medicolegal Affairs (VALVIRA) has approved the collection of tissue samples at autopsy and allowed their use for research. Informed consent from the subjects or their relatives was obtained before the blood samples were collected. For the autopsy a written consent was obtained from the nearest relatives.

\section{RESULTS}

\section{SUBJECTS WITH INTRACEREBRAL HEMORRHAGE}

Seven subjects $(7 / 300,2.3 \%)$ had macroscopic ICH. Three (1\%) had DH, three (1\%) LH, and one (0.3\%) SH. All three subjects with LH had CAA in the microscopic sections were demented and carried the $A P O E \& 4$ allele whereas the subjects with $\mathrm{SH}$ had none of these variables. Of those with $\mathrm{DH}$ none were hypertensive according to the criteria used here. $\mathrm{MH}$ in at least one brain region was found in $186(186 / 300,62 \%)$ subjects and $\mathrm{MH}+$ in $16(5.3 \%)$. The clinical, genetic, and neuropathological data of the subjects with macroscopic hemorrhage (DH, $\mathrm{LH}$, and $\mathrm{SH}$ combined), $\mathrm{MH}$, and $\mathrm{MH}+$ is shown in Table 2.

\section{MICROSCOPIC INTRACEREBRAL HEMORRHAGE}

The majority of the 186 subjects with $\mathrm{MH}$ had a single lesion in one brain region only (Figure 1). Mostly (in 167 subjects, 89.8\%), the lesions consisted of a single siderophage. Three subjects had $2-5$ siderophages and $16(16 / 186,8.6 \%)$ had deposits with $>5$ siderophages $(\mathrm{MH}+)$ in the tissue. All deposits were cortical or leptomeningeal.

Similarly to $\mathrm{MH}$, most subjects with $\mathrm{MH}+(13 / 16,81.2 \%)$ had the lesion in one brain region only (Figure 1). In total there were 22 $\mathrm{MH}+$ lesions in the 16 subjects. The $\mathrm{MH}+$ deposits were invariably $>2 \mathrm{~mm}$ wide. The largest deposits were up to $10 \mathrm{~mm}$ wide and included superficial cortical layers with the above-situated leptomeningeal tissue involved. Subjects with $\mathrm{MH}+$ frequently had cortical MI (Table 2). 12 of the 22 tissue sections (54.5\%) with $\mathrm{MH}+$ also contained an infarct, either cortical MI (4) or a larger lesion. These $\mathrm{MH}+$ lesions were always co-localized with the infarct except in two cases. $\mathrm{MH}$ and $\mathrm{MH}+$ were most prevalent in the parietal lobe (Figure 2).

\section{CORRELATION ANALYSES}

Correlation analyses showed (1) lack of correlation between the presence of $\mathrm{MH} / \mathrm{MH}+$ and the presence of CAA, (2) lack of correlation between the number of brain regions with $\mathrm{MH}$ and the number of brain regions with CAA, and (3) the presence of $\mathrm{MH}+$ correlated with the number of brain regions with CAA (Spearman correlation coefficient $0.129, p=0.026$ ).

\section{MICROSCOPIC INTRACEREBRAL HEMORRHAGE WITH CEREBRAL AMYLOID ANGIOPATHY}

One hundered four subjects (104/300, 34.7\%) had MH and CAA in the same tissue section (MHCAA). Of those 16 subjects with $\mathrm{MH}+, 13(13 / 16,81.2 \%)$ had CAA in the same tissue section $(\mathrm{MH}+\mathrm{CAA})$. Table 3 shows the characteristics of subjects with MHCAA and MH+CAA. Similarly to MH, most subjects with MHCAA (58/104, 55.8\%) had the lesion in one cerebral region only (Figure 1), most frequently in the parietal lobe (Figure 3).

Of the 13 subjects with $\mathrm{MH}+\mathrm{CAA}, 10(76.9 \%)$ had the lesion in a single brain region (Figure 1), altogether 17 lesions were found. These lesions were most frequent in the parietal lobe, similarly to $\mathrm{MH}, \mathrm{MH}+$, and MHCAA (Figure 3). Microscopic analysis of the Prussian blue, $\mathrm{H} \& \mathrm{E}$, Congo red and $\mathrm{A} \beta$-IHC-stained tissue sections of the 17 samples with $\mathrm{MH}+\mathrm{CAA}$ revealed that (1) the width of the area with siderophages roughly correlated with the extent of CAA and (2) the siderophages were located close to CAAvessels, either cortically or leptomeningeally, or both. This became especially clear in the samples with mild CAA, whereas in the samples with severe CAA the number of macrophages close to the CAA blood vessels varied. (3) In most samples (12/17, 70.6\%) with $\mathrm{MH}+\mathrm{CAA}$ the severity of CAA was high (median severity of CAA $>5.3 \%$ ). This becomes even more obvious when the median severity value of CAA in the 17 samples from the 13 subjects with $\mathrm{MH}+\mathrm{CAA}(25 \%)$ was compared with the median severity value of 
Table 2 | Characteristics of subjects with macroscopic and microscopic cerebral hemorrhages.

\begin{tabular}{|c|c|c|c|c|c|}
\hline Variable & Macroscopic hemorrhage ${ }^{a, b}$ & $\mathbf{M H}^{\mathbf{b}}$ & $\mathbf{M H +}$ & Total & OR (p-value) ${ }^{c} \mathrm{MH}+$ vs. $\mathrm{MH}-$ \\
\hline$N(\%)$ & $7(2.3)$ & $186(62.0)$ & $16(5.3)$ & $300(100)$ & \\
\hline Age (years $\pm S D$ ) & $91.5 \pm 1.7$ & $92.4 \pm 3.7$ & $92.7 \pm 4.6$ & $92.4 \pm 3.7$ & NS \\
\hline Dementia & $4(57.1)$ & $116(62.4)$ & $10(62.5)$ & $195(65.0)$ & NS \\
\hline Hypertension ${ }^{d}$ & $0(0)$ & $43(23.2)$ & $5(31.2)$ & $74(24.7)$ & NS \\
\hline$A P O E$ \&3-allele ${ }^{g}$ & $7(100)$ & $171(96.6)$ & $14(87.5)$ & 269 (89.7) & NS \\
\hline$A P O E \varepsilon 4$-allele+ ${ }^{g}$ & $3(42.9)$ & $54(30.5)$ & $10(62.5)$ & $88(31.7)$ & $3.681(0.017)$ \\
\hline Ath & $4(57.1)$ & $117(68.0)$ & $12(80.0)$ & $280(93.3)$ & NS \\
\hline Braak stages 5-6 & $1(14.3)$ & $44(23.7)$ & $5(31.2)$ & $72(24.0)$ & NS \\
\hline CERAD C & $1(14.3)$ & $26(14.0)$ & $2(12.5)$ & $39(13)$ & NS \\
\hline
\end{tabular}

$\mathrm{MH}$, microscopic brain hemorrhage; $\mathrm{MH}+, \mathrm{MH}$ with > 5 pigmented macrophages; OR, Odd's ratio; SD, standard deviation; Antith/antico, antithrombotic/anticoagulation medication; APOE, apolipoprotein E; Ath, atherosclerosis of the cerebral arteries; CAA, cerebral amyloid angiopathy; MI, micro infarction.

${ }^{a}$ Combined counts for the deep, lobar, and subarachnoidal hemorrhages (DH, LH,SH).

${ }^{b}$ Results of the association analyses between macroscopic hemorrhages/MH and the clinical variables NS.

${ }^{c}$ Logistic regression analysis, adjusted for age at death and gender.

${ }^{d}$ Diagnosis based on the use of blood pressure lowering medication.

${ }^{e} \mathrm{ASA}$ in 25, warfarin in 11, dipyridamidole in 11 patients.

${ }^{\dagger} A S A$.

${ }^{g} A P O E$ genotyping performed in 278 subjects.

${ }^{h}$ Focal lesion $\leq 1 \mathrm{~mm}^{2}$ with neuronal loss, glia cell and macrophage reaction and/or cystic tissue necrosis, invisible to the naked eye, analyzed in six brain regions.

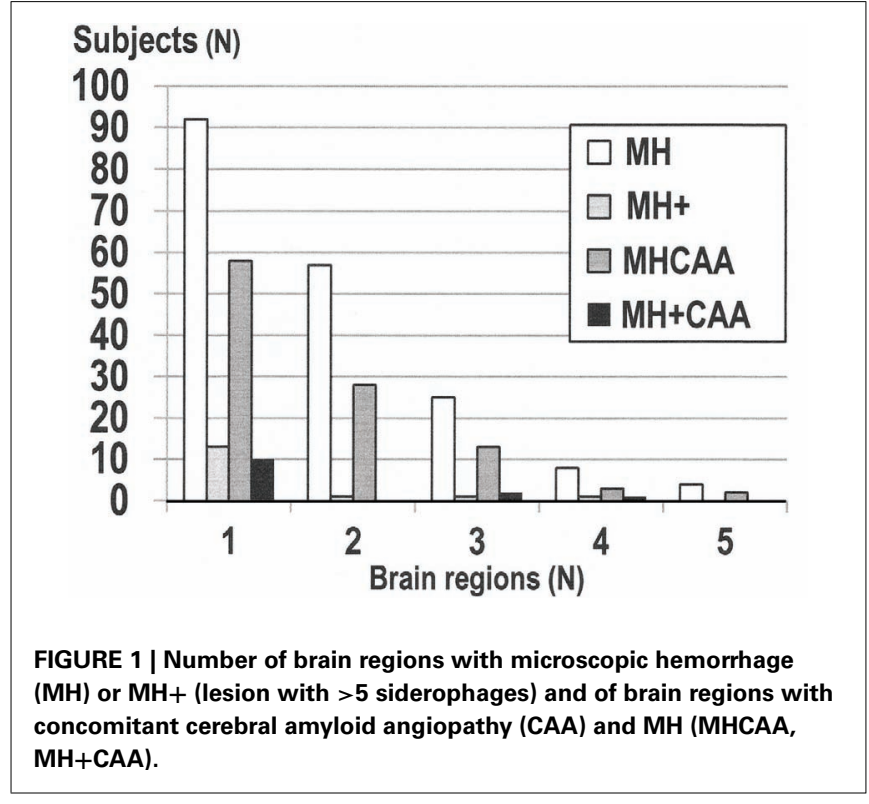

the whole study population (1.0\%, Tanskanen et al., 2012). Similarly to $\mathrm{MH}+$, the siderophages in $\mathrm{MH}+\mathrm{CAA}$ also co-localized with the infarct (Figure 4). (4) The tissue sections from the subjects with $\mathrm{MH}+\mathrm{CAA}$ showed a high number of infarcts (either MI or larger). Altogether 9 infarcts were found, 4 of which were MI. When the hemorrhagic lesion was associated with MI, a small

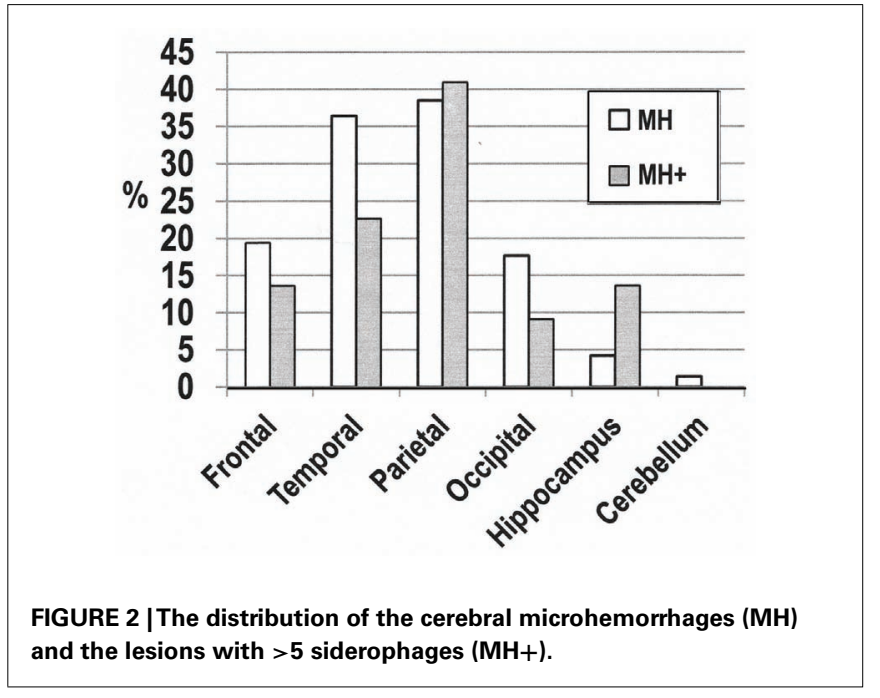

artery was often found in the center/near the center of the lesion, but when in association with larger infarcts it was not possible to show which vessel had bled.

\section{DISCUSSION}

\section{MACROSCOPIC INTRACEREBRAL HEMORRHAGE}

The prevalence of macroscopic ICH (of any type, Table 2) was low $(2.3 \%)$ when compared with a previous populationbased British autopsy study (demented 6\%, non-demented 3\%; 
Table 3 | Characteristics of subjects with microscopic brain hemorrhage $(\mathrm{MH}, \mathrm{MH}+$ ) concomitantly with CAA in the same brain region (MHCAA, $\mathrm{MH}+\mathrm{CAA})$.

\begin{tabular}{|c|c|c|c|c|}
\hline Variable & MHCAA & $\begin{array}{l}\text { OR } \\
(p \text {-value })^{\mathrm{a}}\end{array}$ & $\mathrm{MH}+\mathrm{CAA}$ & $\begin{array}{l}\text { OR } \\
(p \text {-value })^{a}\end{array}$ \\
\hline$N(\%)$ & 104 (55.9) & & $13(81.2)$ & \\
\hline Age $(\text { years } \pm S D)^{b}$ & $92.4 \pm 3.7$ & NS & $93.1 \pm 5.1$ & NS \\
\hline Male gender ${ }^{C}$ & $23(22.1)$ & NS & $5(38.5)$ & $\begin{array}{l}3.267 \\
(0.045)\end{array}$ \\
\hline Dementia & 70 (67.3) & NS & $9(69.2)$ & NS \\
\hline Hypertensiond $^{d}$ & $22(21.4)$ & NS & $3(23.1)$ & NS \\
\hline Antith/antico ${ }^{\mathrm{e}}$ & $12(11.5)$ & NS & $0(0)$ & NS \\
\hline$A P O E$ \&2-allele ${ }^{f}$ & $10(10.1)$ & NS & $3(23.1)$ & NS \\
\hline APOE ع3-allele ${ }^{f}$ & $95(96.0)$ & NS & $11(84.6)$ & $\begin{array}{l}0.159 \\
(0.040)^{\mathrm{g}}\end{array}$ \\
\hline APOE \&4-allele $+^{f}$ & 49 (49.5) & $\begin{array}{l}3.291 \\
(<0.001)\end{array}$ & $10(76.9)$ & $\begin{array}{l}7.522 \\
(0.003)\end{array}$ \\
\hline Ath & 92 (93.9) & NS & $9(75.0)$ & NS \\
\hline Braak stages 5-6 & $35(33.7)$ & $\begin{array}{l}2.294 \\
(0.003)\end{array}$ & $4(30.8)$ & NS \\
\hline CERAD C & $21(20.2)$ & $\begin{array}{l}2.445 \\
(0.011)\end{array}$ & $2(15.4)$ & NS \\
\hline Cortical MIh & 41 (39.8) & NS & 7 (53.8) & NS \\
\hline
\end{tabular}

CAA, cerebral amyloid angiopathy; $\mathrm{MH}$, microscopic hemorrhage; $\mathrm{MH}+$, microscopic hemorrhage with > 5 pigmented macrophages; OR, Odd's ratio; SD, standard deviation; Antith/antico, antithrombotic/anticoagulation medication; APOE, apolipoprotein E; Ath, atherosclerosis of the cerebral arteries; MI, microinfarction.

${ }^{a}$ Adjusted for age at death and gender.

${ }^{b}$ Adjusted for gender.

${ }^{c}$ Adjusted for age at death.

${ }^{d}$ Diagnosis based on the use of blood pressure lowering medication.

${ }^{e} A S A$ in 25, warfarin in 11, dipyridamidole in 11 patients.

${ }^{\dagger} A P O E$ genotyping performed in 278.

${ }^{g} B=-1.838$ (negative correlation).

${ }^{h}$ Focal lesion $\leq 1 \mathrm{~mm}^{2}$ with neuronal loss, glia cell and macrophage reaction and/or cystic tissue necrosis, invisible to the naked eye, analyzed in six brain regions.

Neuropathology Group, Medical Research Council Cognitive Function and Aging Study, 2001). The prevalence of DH was low $(1 \%)$ and the prevalence of LH high (1\%) when compared with the prevalence counts in younger subjects (Lavados et al., 2010). The APOE \&4 allele was common in $\mathrm{LH}$, similarly to a previous study (Biffi et al., 2010). We did not detect an overrepresentation of $A P O E \varepsilon 2$-allele, not even in the subjects with LH that would have been expected based on previous investigations (McCarron and Nicoll, 1998). The likely reason for this seems to be (1) the considerably high mean age and (2) low prevalence of $A P O E$ \&2-allele in the study population (Table 1). Two of the three subjects with $\mathrm{DH}$ had both arteriosclerotic changes in the cerebral blood vessels and the APOE $\varepsilon 4$ allele, the established risk factor for atherosclerosis (Mahley and Rall, 2000), whereas none had hypertension. Because of the low number of subjects with $\mathrm{DH}$ and how the diagnosis of hypertension was obtained, the present study does not allow further conclusions regarding

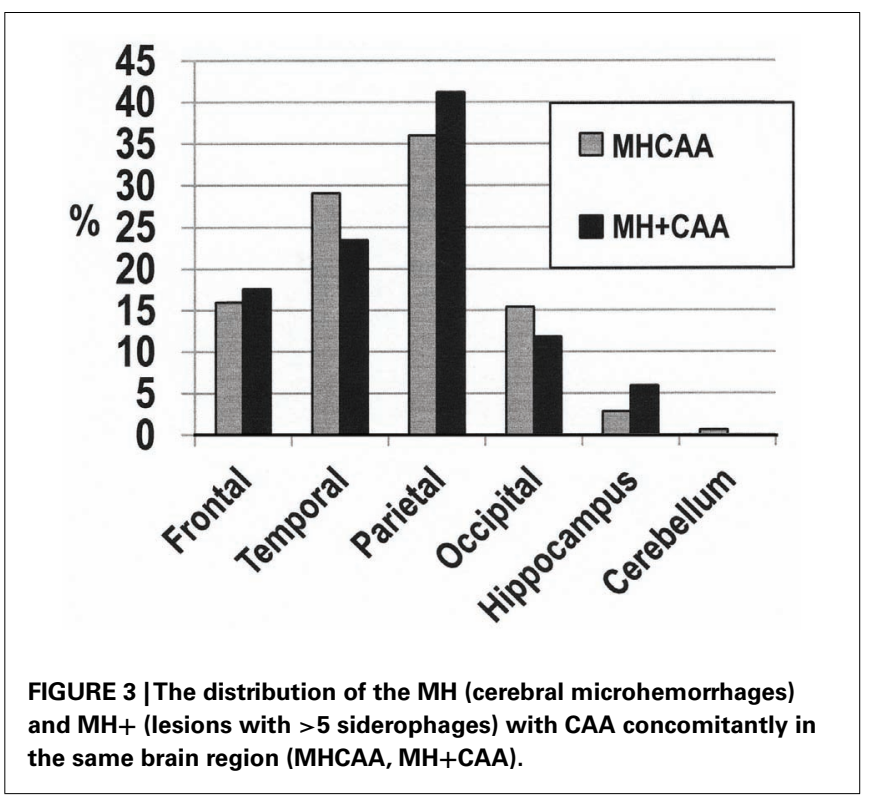

the risk of ICH in hypertensive elderly patients. Similarly, the number of subjects using antithrombotic/anticoagulation medication was relatively small. Interestingly, every subject with $\mathrm{LH}$ was demented, which is in contrast with the younger patients who mostly are non-demented before the first bleed (Mandybur, 1986). Putative explanations include (1) the carriership of the APOE $\varepsilon 4$ allele (all three patients) and (2) atherosclerosis of the cerebral arteries (present in two of the three patients). This is supported by findings that both of these variables are associated with dementia (Mortimer et al., 2009).

\section{MICROSCOPIC INTRACEREBRAL HEMORRHAGE}

$\mathrm{MH}$ was frequent and not associated with any of the clinical, genetic or neuropathological variables investigated (Table 2). Although more than half of the subjects with $\mathrm{MH}$ had concomitant CAA in the same brain region (Table 3), $\mathrm{MH}$ and CAA were not correlated. $\mathrm{MH}$ was cortical/leptomeningeal, in agreement with a previous histological study of patients with neurodegenerative dementia showing mainly cortical deposits (De Reuck et al., 2011).

The frequency of $\mathrm{MH}+$, in contrast, was very low (16/300, $5.3 \%$ ) when compared with the frequency in the population-based MRI studies of younger patients (15.3 and 11.1\% (Sveinbjornsdottir et al., 2008; Poels et al., 2010). The obvious reason lies in the methodological differences. The whole brain tissue cannot be analyzed in the microscope, whereas the MRI scan detects large brain areas at a glance-apparent advantage of the method.

The subjects with $\mathrm{MH}+$ over expressed the APOE \&4 allele (Table 2), as has been previously shown in subjects with microbleeds (Sveinbjornsdottir et al., 2008; Vernooij et al., 2008; Poels et al., 2011).

\section{MICROSCOPIC INTRACEREBRAL HEMORRHAGE WITH CEREBRAL AMYLOID ANGIOPATHY}

$\mathrm{MH}+$ was invariably close to CAA in the tissue sections (although not necessarily vice versa), and so our results are in agreement 

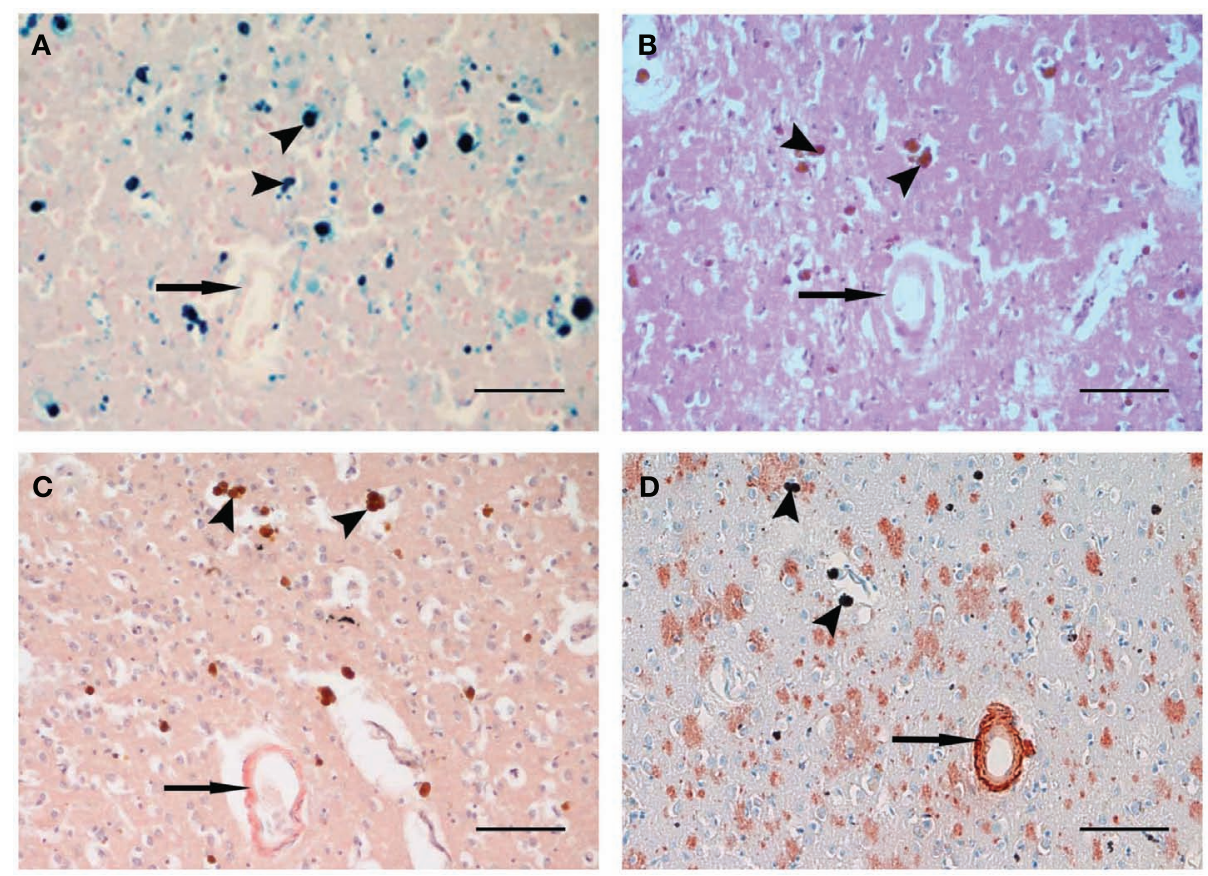

FIGURE 4 | Siderophages (arrow head) close to a small blood vessel with CAA (arrow) in the frontal cortex with subacute infarction. (A) Prussian blue, (B) H\&E, (C) Congo red, (D) immunohistochemistry against amyloid beta $(A \beta)$ peptide. Original magnification $\times 200$. Scale bar $100 \mu \mathrm{m}$. with a previous study (Schrag et al., 2010) which showed $A \beta$ protein in the ruptured blood vessels in the histological samples of microbleeds. Moreover, the severity of CAA in the samples with $\mathrm{MH}+\mathrm{CAA}$ was clearly higher than the severity of CAA in the whole population. This finding confirms previously published data (Greenberg and Vonsattel, 1997), suggesting that severe CAA would be a pre-requisite for bleeding in CAA. It is clear that CAA and $\mathrm{MH}$ differ from each other significantly in the terms of the width of distribution. CAA is wide-ranging (Tanskanen et al., 2012) whereas MH is preferentially local (Figure 1), and not all CAA-lesions, although they would be severe, do bleed. Therefore, a question is raised, that if there are other causes for $\mathrm{MH}$ in the subjects with CAA.

Subjects with $\mathrm{MH}+$ had an unexpectedly high number of MI anywhere in the brains (Table 2). The proportion of subjects with $\mathrm{MI}$ in those with MH+CAA was also high (Table 3) when compared with those with MHCAA (Table 3). The difference however was not statistically significant, - probably due to the small number of subjects with $\mathrm{MH}+\mathrm{CAA}$. However, microscopic examination showed that most of the tissue samples with both $\mathrm{MH}+(12 / 22)$ and MH+CAA (9/17) associated with an infarct (Figure 4) either MI or larger in the histological sections. Furthermore, the siderophages $(>5)$ in $\mathrm{MH}+$ and $\mathrm{MH}+\mathrm{CAA}$ nearly always colocalized with the infarction. Thus, it seems that the hemorrhagic transformation in the infarction may be an important cause for $\mathrm{MH}+$ in the very elderly. A previous study indeed showed that ischemic stroke predisposes to new microbleeds (Gregoire et al., 2010).

The over-representation of the APOE $\varepsilon 4$ allele was even stronger in the subjects with MHCAA (Table 3 ) and especially strong in the subjects with $\mathrm{MH}+\mathrm{CAA}$ (Table 3). APOE $\varepsilon 4$ is also a risk factor for CAA, and therefore the association between $\mathrm{MH}$ and $A P O E \varepsilon 4$ may just be the consequence of CAA in these subjects. Interestingly, MHCAA was weakly associated with AD-pathology (Braak stages 5-6 and CERAD score C) whereas MH+CAA was not, probably due to the small number of subjects with $\mathrm{MH}+\mathrm{CAA}$. MH+CAA associated weakly with male gender, conceivably due to the higher prevalence of CAA in males in our study population (Tanskanen et al., 2012).

\section{MRI AND HISTOPATHOLOGY CORRELATIONS}

Even though our study did not include imaging techniques, it is intriguing to speculate about the histopathological counterparts of the radiologically detected microbleeds, especially (1) which is the role of CAA, and (2) are the MIs involved? We found that MH+ (but not $\mathrm{MH}$ ) associated with APOE $\varepsilon 4$, similarly to the microbleeds. However, this was true for MH+CAA and MHCAA as well. It has also been suggested that there is a topographic association between the radiologically detected microbleeds and CAA (Dierksen et al., 2010), especially in the subjects with AD (Nakata-Kudo et al., 2006), similarly to what was discovered in LH (Greenberg et al., 2004; Ly et al., 2010), referring to the involvement of CAA in the microbleeds. Here the prevalence of $\mathrm{MH}+\mathrm{CAA}$ was highest in the parietal lobe (Figure 3), consistent with the microbleeds (Sveinbjornsdottir et al., 2008; Poels et al., 2011). However, parietal lobe was the predilection site for all other types of lesions $(\mathrm{MH}$, $\mathrm{MH}+, \mathrm{MHCAA}$ ) as well (Figures $\mathbf{2}$ and $\mathbf{3}$ ). The spatial distribution of the lesions as such neither supports nor contrasts the suggestion. Indeed, the high frequency of MHCAA and MH+CAA in the parietal lobe may be due to CAA because the prevalence of CAA in 
the present population was highest in the parietal lobe (Tanskanen et al., 2012).

\section{CONCLUSION}

Macroscopic ICH was rare in the very elderly. $\mathrm{MH}$ was a frequent and innocent lesion. $\mathrm{MH}+$ in contrast was rare and closely related with the APOE $\varepsilon 4$ genotype, the presence of severe CAA and infarction. Further investigations aimed at directly comparing the MRI results with neuropathological data would be of interest.

\section{REFERENCES}

Balami, J. S., Chen, R. L., Grunwald, I. Q., and Buchan, A. M. (2011). Neurological complications of acute ischemic stroke. Lancet Neurol. 10, 357-371.

Biffi, A., Sonni, A., Anderson, C. D., Kissela, B., Jagiella, J. M., Schmidt, H., Jimenez-Conde, J., Hansen, B. M., Fernandez-Cadenas, I., Cortellini, L., Ayres, A., Schwab, K., Juchniewicz, K., Urbanik, A., Rost, N. S., Viswanathan, A., SeifertHeld, T., Stoegerer, E. M., Tomas, M., Rabionet, R., Estivill, X., Brown, D. L., Silliman, S. L., Selim, M., Worrall, B. B., Meschia, J. F., Montaner, J., Lindgren, A., Roquer, J., Schmidt, R., Greenberg, S. M., Slowik, A., Broderick, J. P., Woo, D., Rosand, J., and International Stroke Genetics Consortium. (2010). Variants at APOE influence risk of deep and lobar intracerebral hemorrhage. Ann. Neurol. 68, 934-943.

Braak, H., and Braak, E. (1991). Neuropathological stageing of Alzheimer-related changes. Acta Neuropathol. 82, 239-259.

De Reuck, J., Deramecourt, V., Cordonnier, C., Leys, D., Pasquier, F., and Maurage, C. A. (2011). Prevalence of small cerebral bleeds in patients with a neurodegenerative dementia: a neuropathological study. J. Neurol. Sci. 300, 63-66.

Dierksen, G. A., Skehan, M. E., Khan, M. A., Jeng, J., Nandigam, R. N., Becker, J. A., Kumar, A., Neal, K. L., Betensky, R. A., Frosch, M. P., Rosand, J., Johnson, K. A., Viswanathan, A., Salat, D. H., and Greenberg, S. M. (2010). Spatial relation between microbleeds and amyloid deposits in amyloid angiopathy. Ann. Neurol. 68, 545-548.

Fazekas, F., Kleinert, R., Roob, G., Kleinert, G., Kapeller, P., Schmidt, R., and Hartung, H. P. (1999). Histopathologic analysis of foci of signal loss on gradient-echo $\mathrm{T} 2 *$-weighted MR images in patients with spontaneous intracerebral hemorrhage: evidence of microangiopathy-related microbleeds. AJNR Am. J. Neuroradiol. 20, 637-642.
Fisher, M., French, S., Ji, P., and Kim, R. C. (2010). Cerebral microbleeds in the elderly: a pathological analysis. Stroke 41, 2782-2785.

Greenberg, S. M., Eng, J. A., Ning, M., Smith, E. E., and Rosand, J. (2004). Hemorrhage burden predicts recurrent intracerebral hemorrhage after lobar hemorrhage. Stroke 35, 1415-1420.

Greenberg, S. M., and Vonsattel, J. P. (1997). Diagnosis of cerebral amyloid angiopathy. Sensitivity and specificity of cortical biopsy. Stroke $28,1418-1422$.

Gregoire, S. M., Brown, M. M., Kallis, C., Jager, H. R., Yousry, T. A., and Werring, D. J. (2010). MRI detection of new microbleeds in patients with ischemic stroke: five-year cohort follow-up study. Stroke 41, 184-186.

Koeppen, A. H., Dickson, A. C., and McEvoy, J. A. (1995). The cellular reactions to experimental intracerebral hemorrhage. J. Neurol. Sci. 134(Suppl.), 102-112.

Lavados, P. M., Sacks, C., Prina, L., Escobar, A., Tossi, C., Araya, F., Feuerhake, W., Galvez, M., Salinas, R., and Alvarez, G. (2010). Incidence of lobar and non-lobar spontaneous intracerebral haemorrhage in a predominantly Hispanic-Mestizo population - the PISCIS stroke project: a community-based prospective study in Iquique, Chile. Neuroepidemiology 34, 214-221.

Ly, J. V., Donnan, G. A., Villemagne, V. L., Zavala, J. A., Ma, H., O’Keefe, G., Gong, S. J., Gunawan, R. M., Saunder, T., Ackerman, U., TochonDanguy, H., Churilov, L., Phan, T. G., and Rowe, C. C. (2010). 11C-PIB binding is increased in patients with cerebral amyloid angiopathy-related hemorrhage. Neurology 74, 487-493.

Mahley, R. W., and Rall, S. C. Jr. (2000). Apolipoprotein E: far more than a lipid transport protein. Annu. Rev. Genomics Hum. Genet. 1, 507-537.

Mandybur, T. I. (1986). Cerebral amyloid angiopathy: the vascular pathology and complications. J. Neuropathol. Exp. Neurol. 45, 79-90.

McCarron, M. O., and Nicoll, J. A. (1998). High frequency of apolipoprotein E epsilon 2

\section{ACKNOWLEDGMENTS}

We thank Dr. Tuomo Polvikoski for performing the autopsies. The skillful assistance of Mrs., Tuija Järvinen and Mrs., Merja Haukka in processing of the tissue sections and IHC is gratefully acknowledged. The study was supported by Finska Läkaresällskapet, Liv och Hälsa Foundation, Päivikki and Sakari Sohlberg Foundation and Helsinki University Central Hospital competitive research fund (EVO).

allele is specific for patients with cerebral amyloid angiopathy-related haemorrhage. Neurosci. Lett. 247, 45-48.

Mirra, S. S., Heyman, A., McKeel, D., Sumi, S. M., Crain, B. J., Brownlee, L. M., Vogel, F. S., Hughes, J. P., van Belle, G., and Berg, L. (1991). The Consortium to establish a registry for Alzheimer's disease (CERAD). Part II. Standardization of the neuropathologic assessment of Alzheimer's disease. Neurology 41, 479-486.

Mortimer, J. A., Snowdon, D. A., and Markesbery, W. R. (2009). The effect of APOE-epsilon4 on dementia is mediated by Alzheimer neuropathology. Alzheimer Dis. Assoc. Disord. 23, 152-157.

Myllykangas, L., Polvikoski, T., Reunanen, K., Wavrant-De Vrieze, F., Ellis, C., Hernandez, D., Sulkava, R., Kontula, K., Verkkoniemi, A., Notkola, I. L., Hardy, J., Perez-Tur, J., Haltia, M. J., and Tienari, P. J. (2002). ApoE epsilon3-haplotype modulates Alzheimer beta-amyloid deposition in the brain. Am. J. Med. Genet. 114, 288-291.

Nakata-Kudo, Y., Mizuno, T., Yamada, K., Shiga, K., Yoshikawa, K., Mori, S., Nishimura, T., Nakajima, K. and Nakagawa, M. (2006). Microbleeds in Alzheimer disease are more related to cerebral amyloid angiopathy than cerebrovascular disease. Dement. Geriatr. Cogn. Disord. 22, 8-14.

Neuropathology Group. Medical Research Council Cognitive Function and Aging Study. (2001). Pathological correlates of lateonset dementia in a multicentre, community-based population in England and Wales. Neuropathology group of the medical research council cognitive function and ageing study (MRC CFAS). Lancet 357, 169-175.

Poels, M. M., Ikram, M. A., van der Lugt, A., Hofman, A., Krestin, G. P., Breteler, M. M., and Vernooij, M. W. (2011). Incidence of cerebral microbleeds in the general population: the Rotterdam Scan Study. Stroke 42, 656-661.
Poels, M. M., Vernooij, M. W., Ikram, M. A., Hofman, A., Krestin, G. P., van der Lugt, A., and Breteler, M. M. (2010). Prevalence and risk factors of cerebral microbleeds: an update of the Rotterdam scan study. Stroke 41(Suppl. 10), 103-106.

Qureshi, A. I., Tuhrim, S., Broderick, J. P., Batjer, H. H., Hondo H., and Hanley, D. F. (2001) Spontaneous intracerebral haemorrhage. N. Engl. J. Med. 344, 1450-1460.

Schrag, M., McAuley, G., Pomakian, J., Jiffry, A., Tung, S., Mueller, C., Vinters, H. V., Haacke, E. M., Holshouser, B., Kido, D., and Kirsch, W. M. (2010). Correlation of hypointensities in susceptibilityweighted images to tissue histology in dementia patients with cerebral amyloid angiopathy: a postmortem MRI study. Acta Neuropathol. 119, 291-302.

Sveinbjornsdottir, S., Sigurdsson, S., Aspelund, T., Kjartansson, O., Eiriksdottir, G., Valtysdottir, B., Lopez, O. L., van Buchem, M. A., Jonsson, P. V., Gudnason, V., and Launer, L. J. (2008). Cerebral microbleeds in the population based AGES-Reykjavik study: prevalence and location. J. Neurol. Neurosurg. Psychiatr. 79, 1002-1006.

Tanskanen, M., Lindsberg, P., Tienari, J., Polvikoski, T., Sulkava, R. Verkkoniemi, A., Rastas, S., Paetau, A., and Kiuru-Enari, S. (2005). Cerebral amyloid angiopathy in a 95+ cohort: complement activation and apolipoprotein E (ApoE) genotype. Neuropathol. Appl. Neurobiol. 31, 589-599.

Tanskanen, M., Mäkelä, M., Myllykangas, L., Notkola, I. L., Polvikoski, T. Sulkava, R., Kalimo, H., and Paetau, A. (2012). Prevalence and severity of cerebral amyloid angiopathy - a population-based study on very elderly Finns (Vantaa 85+) Neuropathol. Appl. Neurobiol. 38, 329-336.

Vernooij, M. W., van der Lugt, A., Ikram, M. A., Wielopolski, P. A., Niessen, W. J., Hofman, A., Krestin, G. P., and Breteler, M. M. (2008). Prevalence 
and risk factors of cerebral microbleeds: the Rotterdam scan study. Neurology 70, 1208-1214.

Vinters, H. V., and Gilbert, J. J. (1983). Cerebral amyloid angiopathy: incidence and complications in the aging brain. II. The distribution of amyloid vascular changes. Stroke 14, 924-928.

Yamada, M. (2002). Risk factors for cerebral amyloid angiopathy in the elderly. Ann. N. Y. Acad. Sci. 977, 37-44.

Zhao, X., Grotta, J., Gonzales, N., and Aronowski, J. (2009). Hematoma resolution as a therapeutic target: the role of microglia/macrophages. Stroke 40(Suppl. 3), 92-94.

Conflict of Interest Statement: The authors declare that the research was conducted in the absence of any commercial or financial relationships that could be construed as a potential conflict of interest.

Received: 28 February 2012; accepted: 09 June 2012; published online: 28 June 2012.

Citation: Tanskanen M, Mäkelä M, Myllykangas L, Rastas S, Sulkava R and Paetau A (2012) Intracerebral hemorrhage in the oldest old: a population-based study (Vantaa 85+). Front. Neur. 3:103. doi: 10.3389/fneur.2012.00103
This article was submitted to Frontiers in Stroke, a specialty of Frontiers in Neurology.

Copyright (c) 2012 Tanskanen, Mäkelä, Myllykangas, Rastas, Sulkava and Paetau. This is an open-access article distributed under the terms of the Creative Commons Attribution Non Commercial License, which permits noncommercial use, distribution, and reproduction in other forums, provided the original authors and source are credited. 